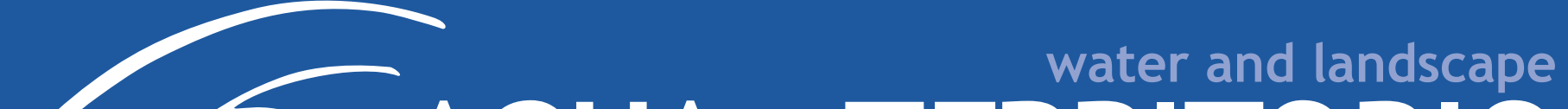 AGUA Y TERRITORIO
}

\section{A inovação na arquitectura termal portuguesa}

\section{La innovación en la arquitectura portuguesa del spa The innovation in Portuguese spa architecture}

Jorge Mangorrinha

Universidade Lusófona de Humanidades e Tecnologias. Lisboa, Portugal. jorge.mangorrinha@ulusofona.pt

Helena Gonçalves-Pinto Universidade de Lisboa. Lisboa, Portugal. hgpinto@gmail.com

Resumo - 0 espaço físico sempre foi essencial à evolução histórica do termalismo. A arquitectura termal afimou-se como um ramo da ciência especializada, articulando planos e programas disciplinares da geologia, engenharia e medicina. As premissas higienistas oitocentistas traduziram-se em soluções construtivas e arquitectónicas, onde o desenho e a singularidade da forma significam, na cenografia ideal, um esforço criado para a "arte de curar", fazendo um jogo e uma deambulação entre o que é imposto pela prescrição médica e os rituais de lazer sugeridos pelo quotidiano do aquista. De forma inovadora, 0 microcosmo termal português também se afirmou com valores próprios, soluções engenhosas e arquitectura adequada aos investimentos possíveis. Ontem, como hoje, Portugal teve e tem, nas suas estâncias termais, um potencial de desenvolvimento, com a criatividade a ter um papel importante na construção de ambientes propícios à promoção da saúde e do lazer.

Resumen - El espacio físico siempre ha sido esencial en la evolución histórica de la hidroterapia. La arquitectura del spa se ha consolidado como una rama especializada de la ciencia, la articulación de los planes y programas de disciplina de la geología, la ingeniería y la medicina. Los higienistas del siglo XIX fueron los que dieron soluciones constructivas y arquitectónicas, donde el diseño y la singularidad de las formas significaban una escenografía ideal, a un esfuerzo creado por el "arte de curar", creando un juego que se extiende entre lo que se requiere de un tratamiento médico prescrito y los rituales de ocio sugeridas por la vida diaria del paciente o cliente térmica (acquista). De manera innovadora, el microcosmos termal portugués también tuvo sus propios valores, soluciones ingeniosas y una arquitectura apropiada adecuada a las posibles inversiones. En sus balnearios, Portugal tiene y sigue teniendo una fuente potencial de desarrollo, que creativamente jugará un papel importante en la construcción de ambientes que promueven la salud y el ocio.

Abstract - The physical space has always been central to the historical evolution of thermalism. The spa architecture asserted itself as a specialized branch of science, articulating plans and disciplinary programs of geology, engineering and medicine. Nineteenth-century hygienists' assumptions were translated into constructive and architectural solutions where the design and uniqueness of form signify, in an ideal scenography, an effort created for the "art of healing", creating an interplay that straddles between what is required by the medical prescription and the rituals of leisure suggested by the daily life of the patient or thermal costumer (aquista). Innovatively, the Portuguese thermal microcosm also had its own values, ingenious solutions and an appropriate architecture suitable to possible investments. In its spas, Portugal has and continues to have a potential source of development, which creatively will play an important role in building environments that promote health and leisure.

Palavras chave: turismo; termalismo; arquitectura; inovação; Portugal Palabras clave: turismo; termalismo, arquitectura; inovación; Portugal Keywords: tourism; thermalism; architecture; innovation; Portugal 


\section{A EVOLUÇÃO DO TERMALISMO: SAÚDE, LAZER E TURISMO}

\section{O PROTO-TURISMO}

0 termalismo, enquanto actividade simultaneamente de saúde e lazer, antecedeu e acompanhou outras manifestações sociais. No seu conjunto, estas estimularam a criação das formas proto-turísticas, que foram propulsoras de novos quotidianos, ambientes e da criatividade, tal como se passou nas termas e arquitecturas associadas, pelo que importa sintetizar a evolução europeia e portuguesa em particular.

Imagem 1. Hospital Termal das Caldas da Rainha, Circa 1870 (80)

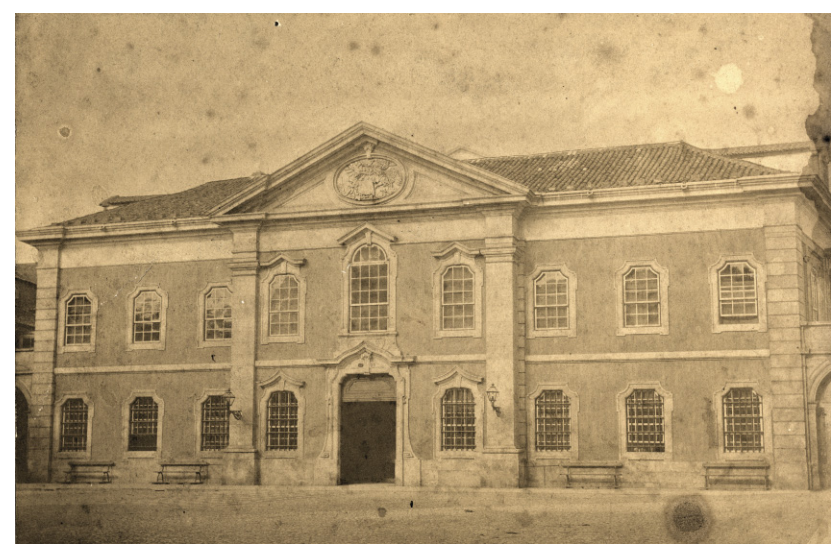

Silva, J. R. (fot.)

0 renascimento dos princípios filosóficos e das artes grecoromanas associou-se ao esplendor que as cortes europeias conferiram à experiência da viagem e, nesta, ao usufruto de antigas ou novas termas, o que implicou, por exemplo, a construção de palácios acastelados e a abertura de novas vias de comunicação por essa Europa fora. Foi em França que esta vida palaciana nas termas adquiriu maior voga no tempo dos Valois e, depois, com a corte faustosa dos Bourbons, seguida por outras casas europeias, designadamente em Portugal, na corte de D. João V, mas sem 0 mesmo esplendor de Luís XIV, em França. Nas Caldas da Rainha, estância termal da corte portuguesa, refundou-se em Setecentos o seu hospital termal, que já tinha sido pioneiro no final do século $\mathrm{XV}$, como o primeiro do mundo com assistência médica e paramédica.

Romancistas, dramaturgos, poetas e historiadores registaram a vida mundana nas termas portuguesas e à escala europeia, divulgando as paisagens e os costumes. 0 impacte do Grand-Tour na história representou uma mudança nos modos de vida e no olhar perante o mundo e no conhecimento que dele se ia tendo, apesar de não se detectar uma lógica esboçada de formalização da experiência turística. As "viagens de prazer" tiveram o seu início nos últimos anos do século XVIII e primeiros do século seguinte, ao mesmo tempo que se geraram grandes mudanças na sociedade, nos estilos de vida, na indústria e na tecnologia ${ }^{1}$. As

10 século XVIII traz um grande incremento nas viagens, sobretudo na Inglaterra. Em 1734, dá-se a fundação, em Londres, do Clube dos Dilettanti, reunindo ex-viajantes a Itália; em 1774, é fundado o primeiro hotel familiar, em Convent Garden; em 1778, Richard Cox funda a agência Cox \& Company, transformada em representações da viagem sofreram uma mudança significativa ao passarem a ser encaradas como experiência aprazível de ascensão cultural dos círculos civilizacionais, em resultado da objectivação científica e da representação estética da natureza². Neste movimento, couberam preocupações ao nível da saúde. Eram comuns viagens para lugares que oferecessem banhos considerados medicinais. A possibilidade de viajar, aliando a ideia de terapia de cura com os banhos, era inicialmente restrita à aristocracia, na maior parte dos países europeus mas, em Portugal, as Caldas da Rainha beneficiavam, simultaneamente, dos utentes de maiores posses e dos mais desfavorecidos.

$\mathrm{Na}$ sua origem, os sítios termais foram frequentados por crentes na cura que aí se deslocavam diariamente, correspondendo à forma mais primitiva do "ir a banhos", aportuguesamento das expressões "aller aux eaux", "taking the cure" ou "taking the waters", que incorporam um conjunto de motivações e atractivos complementares à cura ou mesmo prescindindo dos banhos e, sobretudo, uma estada mais ou menos prolongada de lazer. Este "termalismo de corte" motivava-se, não só com as águas, mas sobretudo com os "pleasure places", onde os edifícios eram cenários de ritos burgueses que deambulam nas praças e galerias. Os outros utentes faziam-no, sobretudo, por necessidade.

Nos alvores do termalismo científico, este foi reconhecido como uma forma incipiente de turismo, realizada por viageiros e veraneantes e reservada à elite, mas que vai evoluindo para uma procura mais abrangente. Molina Villar chama-lhe "geohistória do turismo", localizando-o no período de institucionalização do fenómeno ${ }^{3}$. Uma opinião menos comum é a de Hans Magnus Enzensberger, que num breve ensaio teórico sobre o turismo considera que a origem deste está nas viagens de formação dos jovens por uma série de cortes estrangeiras e, também, no costume de viajar aos balneários para se tomar as águas, sem motivações utilitárias para tratamento ou cura ${ }^{4}$. É precisamente esta motivação sem motivos, a do ócio como objectivo mas como parte das relações sociais, que encontramos nos fluxos para as termas, complementares aos doentes. Trata-se de um conjunto de causas relacionadas entre si, como a razão científica (medicina), a razão sociológica (correntes de pensamento) ou a razão técnica (revolução dos transportes). Molina Villar refere, nesta realidade, as actividades "pseudoturísticas", não exclusivamente turísticas, vinculadas aos

Cox \& Kings, que perdurou até à actualidade; e, finalmente, dá-se o surgimento do sleeping car nas ferrovias e a criação da Wagons Lits, de Georges Nagelmackers. 0 navegador inglês James Cook promove, com Niebuhr, explorador da Arábia, as viagens científicas, que fizeram progredir os conhecimentos da oceanografia. Já no século XIX, a ferrovia Liverpool-Manchester prioriza o transporte de passageiros, a partir de 1841, e Thomas Cook realiza, entre 1841 e 1872, com espírito inicialmente filantrópico e depois mercantil, as primeiras viagens em grupo por Inglaterra, Irlanda, França, Estados Unidos, Terra Santa, Síria, Egipto e Palestina. Em 1871, realiza a primeira viagem à volta do mundo. Edita guias e introduz 0 voucher hoteleiro, sendo considerado o fundador da primeira agência de viagens turísticas, a Thomas Cook \& Son (depois absorvida pela Companhia Internacional de Vagões-Leitos), cujo principal concorrente é o alemão Louis Stangen. Nesta época, é intensificado o transporte marítimo de passageiros entre a Europa e a América, sobretudo por questões de emigração, mas que as viagens de lazer também beneficiariam.

2 Santos, 2001, 177.

3 Molina Villar, 2004.

4 Enzensberger, 1996. 
tratamentos centrados na corrente higienista da medicina, com acções desde 0 âmbito da hidrologia, da climatologia e do contacto com a natureza, face à falta de salubridade dos núcleos industriais urbanos ${ }^{5}$.

A elite emergente na Europa Central, caracterizada pela alta sociedade e por profissionais liberais, dispôs de tempo e meios para viajar, à descoberta de novos territórios, apresentando traços reveladores de uma dinâmica pouco aparentada com as motivações de viagem dos tempos anteriores. A viagem passou a estar associada à busca do exotismo de paisagens e costumes, assim como de climas mais amenos. As viagens e descrições de escritores e intelectuais evidenciaram e divulgaram as características dos diferentes lugares e territórios, estabelecendo uma linguagem positiva do cosmopolitismo, neologismo da época que confere aos europeus o estatuto de "cidadãos do mundo"6.

Foi, neste contexto, que a componente turística do termalismo se definiu no ócio, no tempo livre, nas distracções e no veraneio. 0 folgar complementa o curar, o lúdico substitui o sofrimento, correspondendo deste modo o período de tratamento ao período de folga. A "quinzena" pode, de facto, ser observada como uma "estadia de cura e prazer".

0 veraneio e o movimento de aquistas, acompanhados de tempo livre e de contacto com a natureza, foram uma importante fonte de ingressos nas termas, a par dos investimentos de sociedades compostas por capitalistas exógenos aos locais, ou mistas, integrando neste caso pequenos investidores locais. Foi em resultado destes factores que o termalismo contribuiu, efectivamente, para o início e a consolidação do turismo europeu, como actividade económica associada ao desenvolvimento industrial e para a construção de novos territórios.

\section{O VILEGIATURISMO}

A frequência termal foi o primeiro movimento de viagem que propiciava a "mudança de ares" que, em Itália e França, tomou, no século XIX, a denominação, respectivamente, de "villegiatura" e "villegiature", ou seja, a vilegiatura como viagem a um local durante uma temporada, para repouso e espairecimento, daí a expressão "vilegiaturista"8. Essa deslocação periódica nos meses climatericamente mais favoráveis permitia uma mudança do quotidiano que, depois, seria reforçada com diversos modos de sociabilidade e, também, de uso das águas. Foi, por isso, que esta forma inicial de fluxos turísticos para as termas não se associou obrigatoriamente à cura pela água como primeira motivação, mas às condições ambientais e sociais favoráveis que estes locais ofereciam aos seus frequentadores veraneantes. Em parte do século XIX, o movimento sanitarista associado às preocupações higiénicas face às doenças e condições sociais da época acabou por ter um papel importante na procura de novos hábitos de vida, com reflexos na frequência de lugares mais sãos. 0 campo correspondia às virtudes que iam escasseando nas cidades industrializadas,

\footnotetext{
5 Molina Villar, 2004, 118.

6 Santos, 2001, 196.

7 Quintela, 2001, 372.

8 Morais, 1943, 473.
}

e as vilas ou pequenas cidades termais, embora urbanizadas, garantiam uma relação saudável com os elementos da natureza, como a água, o ar, o clima e a paisagem.

Imagem 2. Pimentel, E. (des.)

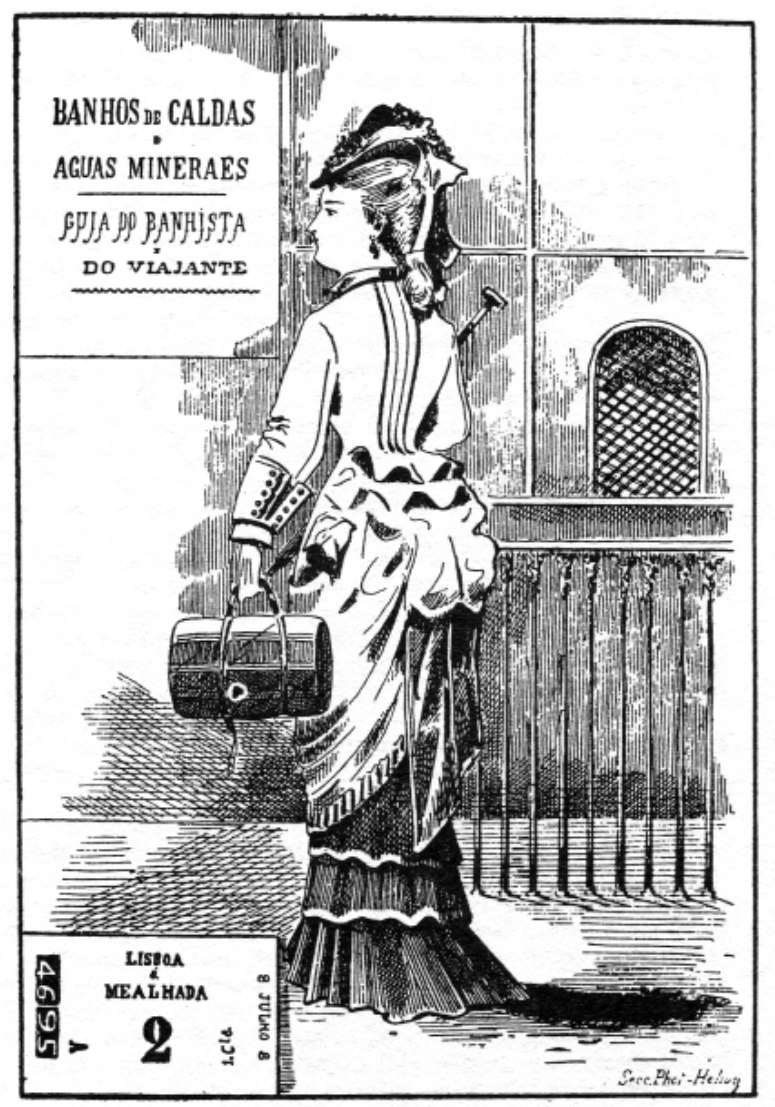

COMBOYO DE CONVALESCENÇA-DE CASA DA ALINE ÁS AGUAS DO LUZO

In: Ortigão, 1875.

As principais termas europeias eram, a par da sua motivação de origem como lugares de terapia, intensamente utilizadas como destino para passar a "temporada", desenvolvendo-se aí um conjunto de distracções associadas a edifícios para esse efeito, como as galerias, os casinos e os clubes de recreio. Esta ambiência, muito frequentada por classes sociais da burguesia e da aristocracia, serviu inclusivamente para refinar uma prática de lazer e para manter viva a cultura termal e as práticas associadas à terapia pela água. Progressivamente, vão sendo propostas actividades diversificadas de recreação, multiplicam-se as construções de hotéis, pensões, casinos e rasgam-se parques e jardins, que emolduram este novo modelo de urbanismo.

Em França, houve um progresso verdadeiramente ímpar em meados do século XIX, quando Napoleão III transformou Vichy e Plombières em luxuosas estâncias termais e ditou a lei do perímetro de protecção (1856). Motivado também pela acessibilidade crescente que o caminho-de-ferro possibilitou, o território francês equipou-se com um conjunto expressivo de estâncias termais, de cariz romântico, locais de estada da nobreza, de artistas e 
poetas. Sob o modelo das grandes estâncias alemãs, como BadenBaden, de um modo geral as estâncias termais renasceram e deram origem ao turismo e às férias. Foi o século dos lazeres. A elite passou os meses de verão a recompor-se dos excessos gastronómicos dos numerosos eventos mundanos das estações anteriores, passadas em Monte Carlo, Biarritz, Menton ou nas principais cidades centro-europeias. Os médicos aconselhavam o passeio, para que a água bebida fizesse a sua função, e prescreviam a dança.

Em Espanha, as sucessivas leis de desamortização, de 1837 e 1855, fizeram com que, em poucos anos, as propriedades de fontes, mananciais, balneários, "casas dos banhos", até então na propriedade municipal ou das ordens religiosas, passassem para as mãos de particulares e empresas, o que permitiu novos investimentos e um desenvolvimento crescente do termalismo espanhol até ao final do século, que se reforçou no período da Restauração (1874-1902), no qual se privilegiou a expansão das zonas dominadas pela burguesia emergente e se construíram os grandes hotéis associados às termas ${ }^{9}$. Entre o final do século XIX e 0 início do século seguinte, as termas espanholas foram cada vez mais preenchidas de uma clientela de veraneio que delas se acercavam, pela maior facilidade de transporte e pela modernização das estruturas balneares e hoteleiras. A estas se associavam, na época, os casinos, salões de baile e teatros.

Portugal acompanhou de perto e seguiu influências verificadas desde 0 final do século XVIII nestes países, mas conseguiu aspectos inovatórios, como veremos, depois de sucessivas realizações de Quesitos, bem como a compilação das nascentes termais e suas estruturas, sob o título: Aquilegio medicinal, em que se dá noticia das agoas de Caldas, de fontes, rios, poços, lagoas e cisternas do Reyno de Portugal e dos Algarves que, ou pelas virtudes medicinaes que tem, ou por outra alguma singularidade, são dignas de particular memoria ${ }^{10}$.

Animadas pelo progresso registado na Europa Central, chegavam a Portugal perspectivas optimistas. Vislumbrava-se um futuro promissor, em termos da exploração de águas minerais, desde que as comunicações viárias fossem melhoradas:

“Il est probable que le Portugal ne restera pas longtemps, sous ce
rapport, dans l'etat d'enfance oú je l'ai trouvé à la fin de l'année
1862, et que dans un avenir prochain, la sollicitude d'un gouver-
nement éclaire el l' intelligence d'un pays en voie de progrés se
serviront des moyens curatis puissants que tous les pays avancés
ont su mettre à prifit pour le traitement de certaines maladies, de
certaines diathèses incurables ou très-difficiles à guérir, à modifier
même par les méthodes comunes de la thérapeutique.
La première condition de la réussite des établissements thermaux
est le percement et entretient de routes qui mettront en commu-
nication facile les grands centrês de population avec les stations
thermales du Portugal et relieront ces stations entre elles. N'est-il-
n'ait que quatre routes accessibles aux voitures, et que les chemins
de fer ne soient encore qu'à l'état rudimentaire?"'11.

Em todo o País, o interesse manifestava-se com novos investimentos privados no termalismo, bem registados pelos escritores.

\footnotetext{
9 Sánchez Ferré, 2000, 222

10 Henriques, 1726.

11 Rotureau, 1864, 236-244.
}

As termas conciliam tudo: "mudança de ares, exercício ameno, banhos, copinho peregrinação, entretenimento, vita nuova!..." (Júlio César Machado). As novas estâncias apresentam um aspecto "risonho e alegre" (Pinheiro Chagas) e, por entre os mais ociosos, se encontram também "os sujeitos que não têm que fazer e vão para as Caldas em partida de recreio" (Ramalho Ortigão) ${ }^{12}$. Mas, sem grandes alardes noticiosos, contavam-se aquistas menos endinheirados e indigentes, cuja história clínica ficou registada nos livros de assuntos de doentes, nos atestados de pobreza e nos diários de dietas alimentares (no caso das Caldas da Rainha).

0 desenvolvimento termal em Portugal passou a ser fértil em resultado da lei para a concessão de nascentes de "águas mineromedicinais" (1892), mas também por causa do desenvolvimento das vias e dos transportes terrestres. Não surpreende que tenham sido as mais acessiveis e mais próximas dos principais centros urbanos e das áreas de maior densidade de população as que mais rapidamente progrediram como estâncias dotadas de oferta balnear, hoteleira e comercial. Muitos locais ainda continuaram a ser alcançados por barco, como Caldas de Aregos, Entre-os-Rios e Caldas de Moledo. Caldas da Rainha continuava a impor-se. Havia dois hotéis, duas hospedarias, e durante a estação balnear quase todas as famílias recebiam hóspedes. Os doentes podiam contar de igual modo com 0 alojamento hospitalar. A procura provinha, não só de Lisboa, como também do Brasil e de Espanha. Era já uma procura mesclada de aquistas a necessitarem de tratamento, mas também de veraneantes, realidade que se expressava, não só nas Caldas da Rainha, mas também em Entre-os-Rios, Caldas das Taipas e Luso, por exemplo, cujas motivações passavam pelos seus clubes, parques e matas ${ }^{13}$.

Este desenvolvimento não impedia, contudo, que se fizessem críticas à falta de promoção externa das termas portuguesas ou uma comparação entre a realidade portuguesa e os avanços expressos noutros países, como em França. Em 1902, a propósito da abertura para breve de um estabelecimento termal (com hotel e casino), em Clermond Ferrand, a Gazeta dos Caminhos de Ferro refere sobre a empresa investidora:

\section{"[J]á tem contractos para publicidade em todos os paizes, e em Portugal já se sabe que serão affixados, durante cinco annos 250 bellos cartazes d'um dos mais notaveis desenhadores francezes.}

Em todas as cidades da Europa se annuncia já, n'este momento, por meio dos mais formosos prospectos, o que serão as encantadoras festas do Carnaval de Veneza em 1903!

Pois não consta que lá fóra apareça um único cartaz desenhando as nossas montanhas, as nossas thermas, as nossas praias"14.

\section{A MODA DAS TERMAS}

A par da institucionalização do turismo em Portugal (1911), as primeiras décadas do século XX trouxeram novos meios de transporte e novas possibilidades de deslocação. A invenção e a posterior massificação do automóvel vieram transformar o fenómeno turístico. Os percursos deixaram de estar condicionados

12 Pinto; Mangorrinha, 2003, 167.

13 Cavaco, 1980; 192-196.

14 Gazeta dos Caminhos de Ferro, 307 (1902). 
Imagem 3. Freire, A. J. (des.)

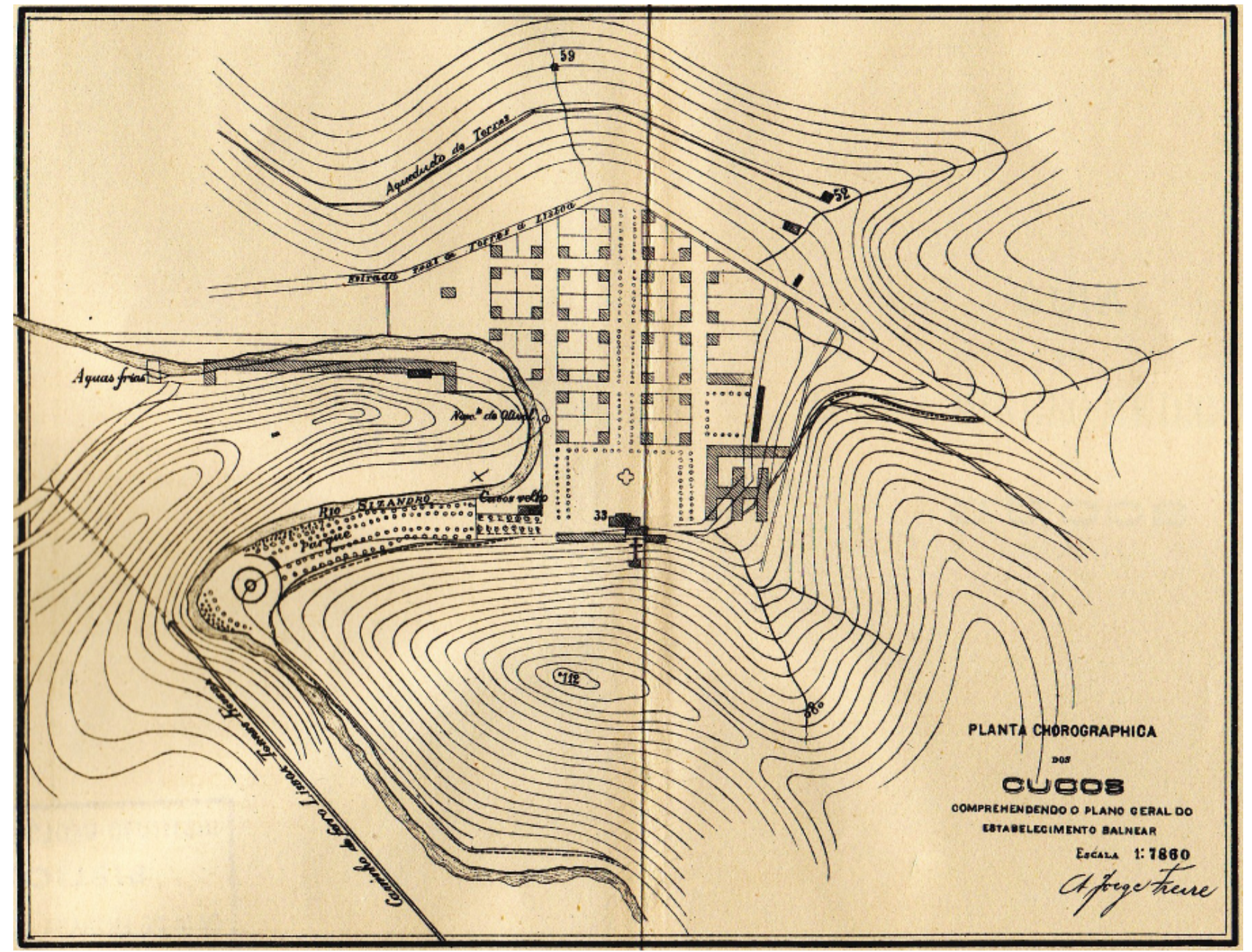

In: Guia das aguas minero-medicinaes...,1892.

pela existência ou não do caminho-de-ferro e de diligências, ou pela disponibilidade de lugares e horários. 0 viajante podia, agora mais livremente, partir quando quisesse e por onde quisesse, utilizando meios de comunicação e de transporte mais diversificados. As regiões mais isoladas ou distantes beneficiariam do desenvolvimento dos veículos automóveis, como seriam os casos de algumas termas do País, a tal ponto que as de Chaves foram nomeadas por Júlio César de Vasconcelos Correia, quando este engenheiro solicitou ao governo a concessão do exclusivo, por 25 anos, do transporte público movido por tracção mecânica.

A viagem lúdica tornou-se num prazer das classes mais favorecidas. As possibilidades trazidas pelo caminho-de-ferro e pelo automóvel, aliadas a novos hábitos em torno de infra-estruturas recentes nas estâncias balneares e termais ou em busca de atractivos nalgumas cidades e vilas do País, levaram a uma intensificação extraordinária da viagem lúdica. Simultaneamente, as viagens ao estrangeiro aumentaram, associadas a um melhor nível de vida da população, que podia lá fora admirar os desenvolvimentos tecnológicos e artísticos recentes, sobretudo nas grandes cidades europeias ${ }^{15}$.

15 Se bem que podemos questionar se foi a "invenção" dos transportes colectivos o que motivou as viagens ou se foi a necessidade de viajar que propiciou
0 novo regime político republicano (1910) representou, também, um aumento da frequência termal em Portugal. A ritualização da sociedade à volta das termas manteve-se mesclada de classes sociais. Na década de 1910, construíram-se edifícios nalgumas das mais importantes estâncias portuguesas, que responderam morfologicamente a exigências e rituais próprios da actividade termal.

$\mathrm{Na}$ época, as termas portuguesas atingiam já grandes diferenças, desde estruturas de pequena dimensão a estâncias dotadas de uma oferta diversificada de balneoterapia, alojamento e comércio. A tutela refere-se sobre o desenvolvimento da "exploração das nossas águas minero-medicinais, que podem constituir

e implusionou a melhoria dos meios de transporte, certo é que os melhoramentos das infra-estruturas viárias facilitaram as deslocações: a construção e melhoria das vias de comunicação -estradas e caminho-de-ferro-, as actividades ligadas à bicicleta ou, mais tarde, o surgimento dos primeiros automóveis no final do século XIX. Algumas destas inovações e a sua difusão permitiram mais facilmente as viagens e obrigaram, por sua vez, à melhoria das infra-estruturas viárias, à modernização da hotelaria e à defesa dos monumentos históricos, elementos estruturantes do produto turístico. 0 período inicial de arranque do caminho-de-ferro na Europa baliza-se entre 1825 e 1848, respectivamente, desde o que foi construído em Inglaterra, de Stockton a Darlington, até ao de Espanha em 1848, de Barcelona a Mataró. 
uma excelente fonte de receita, se forem metodicamente exploradas e lhes fizerem a conveniente propaganda"16.

A construção de unidades hoteleiras em Portugal e nas estâncias termais em particular, que teve um impulso importante na década de 1910, sobretudo ao nível das grandes edificações, não teve uma expressão significativa nas décadas seguintes:

"construíram[-se] alguns francamente confortáveis e em tudo dignos de receberem hóspedes civilizados, mas acrescente-se que é ainda muito pouco para o que necessitamos. Sobretudo na província o problema ainda é angustioso. É urgente melhorar, transformandoos, os que existem, e construir outros novos com uma capacidade média e as condições de conforto e civilização que se impõem"17.

A dimensão dos equipamentos por vezes não representava a maior qualidade, pelo menos atendendo a alguns comentários:

"Se há até Grandes hoteis que teem 6 quartos! Por este andar não
nos surprehenderá um Hotel Palace com uma mobilia de pinho. De camas, então, não fallemos.

É pessimo o habito das nossas povoações do norte, de as ter duras, durissimas, e teimar que isso é mais hygienico, e querer convencer de que todo o mundo anda mal e só nós sômos sabios.

Resultado: para quem viaja, ter o corpo moido, depois de uma noite de descanço; para as terras, vêr que muitos dos visitantes, os estrangeiros que vem aqui, fogem espavoridos ante a perspectiva de ter que dormir repetidas noites sobre os nossos colchões de... corticite.

Raras são as excepções, e parece-nos que ciamos todas se dissermos que colchões habitaveis, no norte, só se encontram nos dois hoteis das Pedras Salgadas, no do Vidago reclamando-o, no 'Gomes e Mattos' de Braga, e no Grande Hotel do Porto"18.

Em contrapartida, o novo estabelecimento das Termas de Santo António, a um quilómetro a Norte da estação de Celorico, motivou comentários elogiosos da parte da Gazeta dos Caminhos de Ferro:

\footnotetext{
"0 estabelecimento tem, na sua pequenez, installações para as diversas applicações hydrotherapicas necessarias para o tratamento das dyspepsias, engorgitamentos do figado e do baço, lithiase biliar, arthirismo, gotta, dermatoses, escrofulismo e outras enfermidades em que essa applicação tem já provado a sua profuidade em numeros doentes.

É modesta a installação, o que não admira sendo feita a cargo de um só proprietario, cuja iniciativa é muito louvavel.

Há hotel, casas para alugar, club, carros para passeios e outras commodidades.

Esta alli o inicio de uma importante estação thermal a que já concorrem alguns centenares de doentes, com bom resultado"19.

Noutra pequena estância (Caldas Santas de Carvalhelhos), o seu concessionário procedia à abertura de uma estrada entre

16 Direcção Geral das Obras Públicas e Minas, 1912, 48.

17 Silva, 1948, 53.

18 Gazeta dos Caminhos de Ferro, 248 (1909).

19 Gazeta dos Caminhos de Ferro, 314 (1915). Nesta reportagem, curiosamente, dá-se conta da iniciativa do Automóvel Clube de Portugal em colocar, pela primeira vez, placas identificativas à entrada das localidades, a que se seguiriam as placas de trânsito nos cruzamentos das estradas.
}

as suas termas e a sede do concelho (Boticas), para fazer face à ausência de caminho-de-ferro até Chaves e ao mau caminho existente até Carvalhelhos. Todavia, a estrada apenas viria a ser finalizada quando os exploradores alemães das minas de volfrâmio de Carvalho tiveram nisso interesse durante a II Guerra Mundial. Até esta altura, as águas engarrafadas eram transportadas, custosamente, à cabeça por mulheres, desde Carvalhelhos, dali até Boticas, em carro de bois, e de Boticas à estação de caminhode-ferro de Vidago, em carro de cavalos.

De 1921 a 1936, em Portugal, as Comissões de Iniciativa acabariam por ter um papel importante no investimento promocional das estâncias termais. Auxiliadas pelo dinamismo das elites locais, que também por esta época se fazia sentir em vários pontos do País, o governo justificou a criação de uma estrutura de base concelhia, para resolver questões de afirmação dos locais e de uma melhor promoção do seu património histórico e cultural.

Nas Termas de Monfortinho, junto da fronteira com Espanha, a falta de meios de comunicação foi o factor decisivo para o escasso desenvolvimento até à entrada dos anos 40, mas que a construção do mais moderno estabelecimento termal até aí realizado em Portugal viria a colocar esta estância num lugar de topo do termalismo nacional. À entrada da década de 1940, os Banhos de S. Paulo, em Lisboa, lideravam o movimento de aquistas em Portugal, ultrapassando os 35.146 banhos, em 1942, seguidos desde logo por Monfortinho, Caldas de Vizela, Caldas da Rainha, Caldas de Aregos, Termas de S. Pedro do Sul e Caldas de Monchique, todas acima dos 10.000 banhos anuais ${ }^{20}$. Não deixa de ser curioso o facto de a tabela ser liderada por realidades geograficamente extremas, a primeira na capital do País e a segunda no interior, junto à fronteira e com poucas condições urbanas e de comunicação, mas com instalações balneares modernas. Relativamente a estâncias nas quais nestes anos se construíram novas instalações termais, a posição relativa entre as mesmas era liderada por Monte Real (2.545 aquistas, em 1942, e 3.326, em 1946), Monfortinho (1.525, em 1942 e 2.836, em 1946) e S. Pedro do Sul (1.431, em 1942, e 1.834, em 1946) ${ }^{21}$.

Durante os anos que se seguiram, sustentava-se:

\begin{abstract}
"[As] nossas Estâncias Termais são preteridas por muitos portugueses em favor das estrangeiras; de que a frequência das nossas Termas é quase insignificante em relação às suas congéneres francesas e italianas, em que é normal haver, numa só Estância, maior movimento de aquistas do que em todas as portuguesas juntas, já não falando na vizinha e amiga Espanha, onde -apesar dos Balneários serem presentemente bastante inferiores aos nossos- se regista uma afluência enorme de portugueses.

Muitos queixam-se de que não temos casinos, piscinas, vida mundana e outros atractivos que encontram lá fora, esquecendo que é precisamente pela preferência dada às Estâncias Estrangeiras, que as nossas não têm tido, na maioria dos casos, possibilidade de realizar aqueles empreendimentos, de que aliás se reconhece a necessidade"22.
\end{abstract}

\footnotetext{
20 Aguiar, 1943, 54.

21 Portugal \& Brito, 1949.

22 Alves, 1951, 17.
} 
As viagens de veraneio tornavam-se numa necessidade social que se democratizava com o despertar de fluxos específicos, do campo para a cidade, para beira-mar ou para as estâncias termais e climatéricas, considerados como espaços com aptidão turística. Inicia-se o período caracterizado pelo fenómeno colectivo de massa em determinados locais, temporalmente regulados, tanto pela função em si (estância de cura ou de veraneio), como pela "experiência agenciada"23.

\section{AS TERMAS E O TURISMO DE MASSAS}

Na segunda metade do século XX, o crescimento exponencial do turismo deveu-se ao progresso económico dos países e das sociedades, ao desenvolvimento dos meios e tecnologias de transporte e de comunicação e às motivações crescentes e diversificadas das populações para a descoberta e o conhecimento de outras partes do mundo. Este quadro conduziu, sobretudo, a um turismo de massas (mais do que um turismo especializado), favorecido pela institucionalização do tempo livre, o que desencadeou a "colonialização do território" e 0 aparecimento de novas tipologias.

Imagem 4. Panorama: revista portuguesa de arte e turismo, II,10-11 (1954)

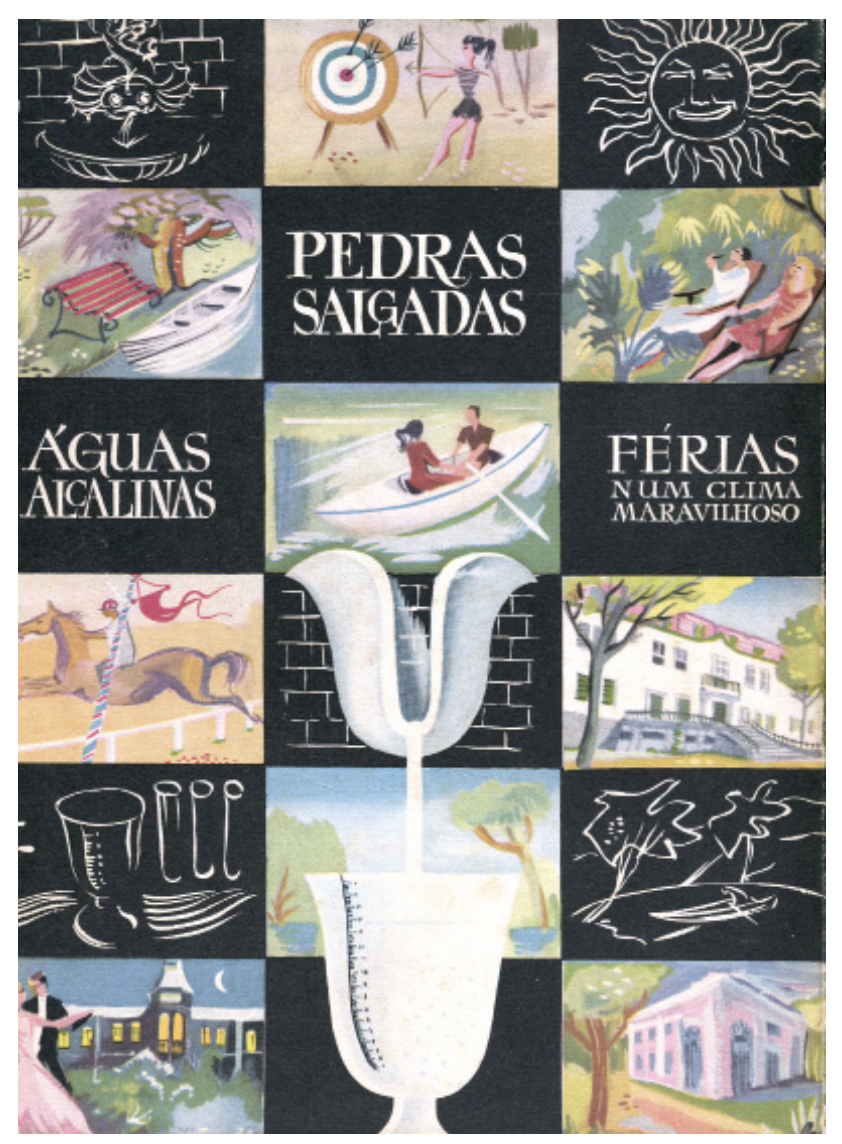

Portugal encontrava-se, no início desse período, em melhores condições de paz que aqueles países mais directamente

\footnotetext{
23 Cohen, 1995, 15.
}

atingidos pela II Grande Guerra. Esta causa trouxe para as termas portuguesas uma nova tipologia de utentes, sobretudo os refugiados da Guerra, mas também novos-ricos decorrentes da emigração para a América do Sul e África. Esta realidade coincidiu com um período caracterizado por aspectos positivos e negativos para o desenvolvimento do termalismo.

À semelhança de outros países europeus, nos anos 50, o Estado português legislou a comparticipação nos tratamentos termais através da Segurança Social, o que conferiu um novo impulso para esta actividade económica. As termas sobreviveram, nesta altura, essencialmente como centros de tratamento e cura.

Pedia-se a realização de um reconhecimento geral das estâncias termais, seguido de um programa de valorização, tendo em conta: 0 estudo, conhecimento e divulgação das propriedades das águas mineromedicinais e das possíveis aplicações; a dotação dos balneários, com as convenientes instalações terapêuticas e pessoal técnico especializado; a construção, renovação e melhoria das instalações hoteleiras e complementares; a dotação das termas como centros de recreio e desporto; a melhoria nos respectivos meios de acesso. Em 1970, já se reclamava a necessidade de as leis do crédito turístico serem alteradas. Recomendava-se, por outro lado, uma ligação à Fédération Internationale du Thermalisme et du Climatisme (FITEC) ${ }^{24}$, a fim de se promover internacionalmente uma divulgação das características e possibilidades das termas portuguesas. Internamente, estas poderiam apoiar 0 desenvolvimento de regiões desfavorecidas. A lenta recuperação nos valores da procura, iniciada nos anos 50, atingiu alguma expressão nos anos 70 , com esporádicas oscilações, durante esse período, motivadas pelas condições político-económicas do País.

Ainda assim, o Estado favoreceu sobretudo o desenvolvimento do turismo de "sol e praia". As praias cresceram como centros de lazer e recreio, favorecendo clientelas estrangeiras e a entrada de divisas. A falta de um Plano Nacional de Desenvolvimento Turístico reduziu a importância de outros produtos turísticos. Assistiu-se a uma estagnação da oferta termal (o que originou situações de saturação) e a uma ausência de investimentos na conservação, renovação e actualização de equipamentos, o que levou a um progressivo abandono e consequente decadência dessas infra-estruturas, diminuindo o seu poder de atracção. Trabalhava-se com muito poucos estímulos, face à necessidade de concorrer com estâncias de outros países.

Anos mais tarde, reflectiu-se intensamente sobre o lugar das termas como pólos de desenvolvimento turístico, desde logo inseridas numa diversificação turística para o País, que dava os primeiros passos, tendo em vista a criação de múltiplas motivações que afectariam a procura, bem como em conferir mais oportunidades para as populações residentes. A identificação do território turístico termal como heterogéneo e caracterizado por componentes inter-relacionadas permitiria garantir, à partida, uma maior fidelização do turista; por outro lado, em matéria estritamente médica, aos avanços da quimioterapia não correspondeu 0 abandono das práticas crenoterápicas que, particularmen-

24 A FITEC foi constituída em 1947, sendo composta por organizações nacionais de termalismo e climatismo e tendo como objectivos acções de representatividade, cooperação e promoção. 
te nas doenças crónicas, mantinham uma eficácia comprovada. Associada a estas práticas, o carácter do lugar, de estância de repouso, correspondia à necessidade de evasão e de prevenção às agressões e tensões sociais e do quotidiano. Considerava-se que vários motivos concorriam para conferir ao termalismo um factor de atracção turística e ao mesmo tempo de garante da sua validade no tempo ${ }^{25}$.

O IV Plano de Fomento (1974-1979) eleva a importância conferida ao sector das termas, consideradas os "únicos centros de apoio ao turismo no interior" e factores de reequilíbrio do desenvolvimento. Tal medida não se revelaria tão eficaz, mas provocaria uma maior participação dos organismos da segurança social nos tratamentos termais. Objectiva-se para o termalismo português:

- Mais divulgação das águas mineromedicinais, visando, em especial, a conquista de mercados externos;

- Mais divulgação das estâncias termais, tendo em atenção, designadamente, um alargamento da época termal;

- Mais divulgação da capacidade das empresas nacionais directamente envolvidas no sector, designadamente, no âmbito de estudos geológicos, sondagens e metalomecânica;

- Dar a conhecer os mais recentes modelos de equipamento nacionais e estrangeiros, para balneários, dada a incidência que poderão ter na actual fase de reapetrechamento das instalações existentes, bem como nas unidades em construção $0^{26}$.

Seria na década de 1980 que o conceito de turismo se transformaria numa organização científica do lazer. A animação turística passou a ser um ramo especializado da animação sociocultural. Vislumbrou-se a entrada do termalismo numa nova era, a propósito das tendências da procura turística e das características da evolução da procura termal. Este momento coincidiu com a vontade generalizada de condicionar o desenvolvimento do sector às necessárias reformas estruturais da oferta. Os esforços dos concessionários e poderes públicos passavam por entender o termalismo, não como a recuperação de modas e práticas do passado, mas por integrar os costumes, os hábitos e as preferências a uma constante adaptação. Por força das chamadas "alterações de estrutura em permanência" nenhuma actividade pode produzir o mesmo, durante gerações, sejam bens ou serviços, se se mantiver na mesma situação de estabilidade ${ }^{27}$. Daí a importância de inovar.

A crise que se prolongara até aos anos 70 , foi depois reduzida quando surgiram alguns apoios financeiros aos tratamentos termais, institucionalizando o chamado "termalismo social" e beneficiando camadas mais desfavorecidas e seniores da população. Esta característica começou a ser acompanhada por outras vertentes, quando surgiram novos programas do denominado turismo "remise en forme", à semelhança de outros países europeus, aproveitando as condições únicas das estâncias termais em termos de qualidade ambiental e paisagística, riqueza patrimonial e tranquilidade.

25 Cunha, 1973, 79.

26 Direcção Geral de Minas e Serviços Geológicos, 1981, 257-258.

27 Cunha, 1981, 72-73.
0 Plano Nacional de Turismo (1986) seleccionou o termalismo como uma área-chave, pela sua importância para atenuar 0 desequilíbrio e assimetrias regionais e por permitir uma maior diversificação da oferta turística nacional. Estes factores, conjuntamente com a necessidade de recuperação das estâncias termais e uma previsão de aumento da procura pela entrada de Portugal para a então Comunidade Europeia, deram origem à criação da Comissão Nacional de Termalismo, na Presidência do Conselho de Ministros. Paralelamente, para definir as linhas de orientação do termalismo e coordenar os vários departamentos governamentais do Estado, consubstanciado, resumidamente, na criação de esquemas de financiamento para a renovação e promoção das estâncias termais. Ao mesmo tempo, foi definido um "Programa Especial de Apoio para a Recuperação, Renovação ou Desenvolvimento de Estâncias Termais".

Nas décadas mais recentes, verificaram-se alterações profundas nos conceitos e nas práticas e valores termais. A generalização do conceito mais abrangente de "turismo de saúde e bem-estar" (2004) trouxe novas perspectivas e esperanças para as termas portuguesas, onde os programas para seniores e jovens infanto-juvenis deveriam ser uma prioridade estratégica, mas cujos números ficaram longe de atingir o desejado. Foram acelerados os projectos de reforma de balneários e de outros edifícios e substituíram-se os aparelhos e equipamentos, em resposta ao progresso das técnicas terapêuticas e à diversificação do programa funcional, tendo em vista uma oferta competitiva num espaço onde é harmoniosa a combinação entre saúde e turismo, lugar idóneo concebido como microcosmo termal.

\section{O MICROCOSMO TERMAL}

A água sempre teve um papel decisivo na ordem dos conjuntos termais (balneários, hotéis, buvettes, pavilhões de nascente, galerias, casinos, parques e jardins). A evolução desta relação foi aperfeiçoada através dos tempos, tal como a arquitectura e a tecnologia aplicada.

A precisão no empirismo do programa termal tem-se baseado mais na lenta experimentação, nos ensinamentos de médicos e hidrólogos, do que em tratados científicos. 0 programa evoluiu com a própria actividade, desde as precárias construções que abrigavam algumas banheiras e tanques -simplesmente designadas por "banhos" ou "casas dos banhos"- aos grandes estabelecimentos termais que tomaram forma prestigiosas e amadurecidas.

No auge do seu crescimento, o microcosmo termal português oitocentista tornou-se no cenário inovador de desenho urbano para onde convergiram aquistas de diferentes origens geográficas e sociais, desenvolvendo-se em torno de uma matriz cultural própria. A urbanização e o loteamento do solo das principais estâncias termais foram um processo dinâmico, o qual permitiu que se criassem novos aglomerados ou malhas continuadoras dos núcleos antigos. Dentro destas estâncias termais, de propriedade privada na sua maioria, a arquitectura termal é, para além dos edifícios balneares, a arquitectura que identifica as terras-de-águas, com edifícios e percursos caracterizadores que contribuem para a consolidação do microcosmo termal, como um todo, onde se cruzam 
rituais de celebração e de encontro social, ao gosto da festa e do imaginário ${ }^{28}$.

Imagem 5. Martinet, H. (des.)

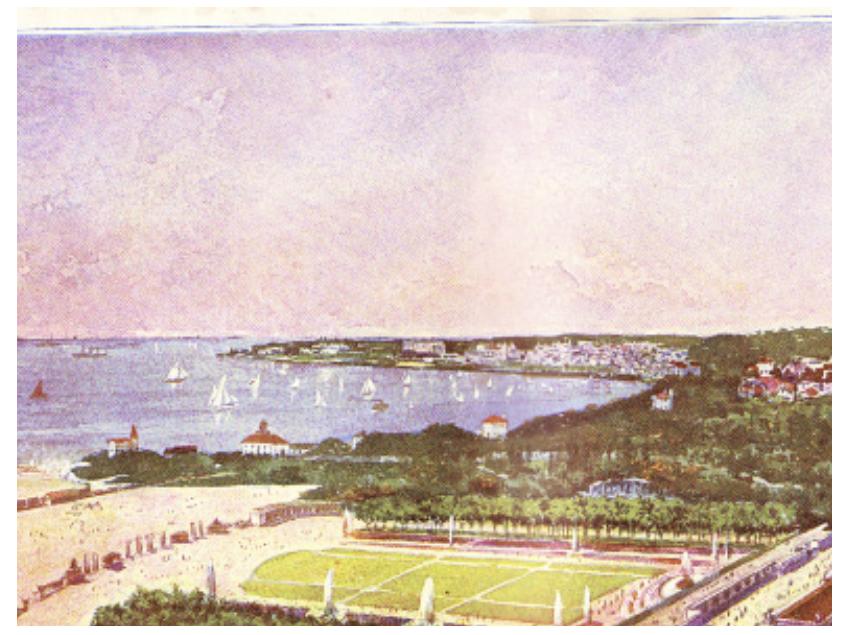

In: Estoril, Estação Marítima...,1914.

Defendemos que há um discurso português que não se alheia, porém, dos paradigmas externos mas, essencialmente, evoca uma utopia própria, como desejo de ir mais além, a busca de novas soluções engenhosas e de formas diferentes das que existiam no território, articulando engenheiros e arquitectos, tarefa essencial nesta arquitectura que, antes de qualquer outra preocupação, deve saber desenhar-se no respeito mais profundo em relação aos percursos da água, como recurso essencial, e dos utentes, como razão de ser do espaço criado ${ }^{29}$.

Cuidada foi a selecção dos materiais empregues, como as alvenarias de pedra e tijolo e o ferro, articulados com os elementos pétreos decorativos. No detalhe desta arquitectura, que se pauta pela ausência de monumentalidade, foi empregue grande cuidado nos percursos internos dos balneários e na selecção dos materiais de revestimento, onde o azulejo, o mosaico decorativo e o vitral ganham um novo relevo, criando cenografias, transmitindo luz e conferindo a melhor propriedade a higiene. Também inovadora foi a indústria que se especializou na construção de equipamentos de hidroterapia, porque traduziu a modernidade e os progressos terapêuticos operados no estrangeiro (França, Alemanha, Bélgica, Espanha). As empresas portuguesas souberam traduzir as necessidades práticas da mecanização do banho e do avanço tecnológico de duches e equipamentos de inalação e pulverização, aperfeiçoando instrumentos terapêuticos, testando materiais (resistência, durabilidade, adequação) e criando novas redes de distribuição de água mineral (quente e fria), águas correntes e de vapor, empregues por uma medicina hidrológica cada vez mais especializada. Os novos aparelhos para banhos de imersão, carbogasosos e de vapor, duches ascendentes, descendentes e locais, ginástica mecânica, massagens aquáticas, inalações e irrigações nasais são apresentados nos grandes certames inter-

\footnotetext{
28 Pinto \& Mangorrinha, 2009.

29 Idem.
}

nacionais e rapidamente seriam instalados nas estâncias termais, nos hospitais e nos edifícios de apoio aos banhos de $\operatorname{mar}^{30}$.

A inovação fez-se sentir em Portugal na conceptualização e na construção do parque termal, encerrado em si mesmo e desenhado de acordo com os preceitos médicos da terapia, da higiene e da salubridade - "foram sujeitos a uma planificação física, incorporando todas as partes que, dependendo umas das outras, passaram a corresponder a uma vida organizada em torno do ritual da água e das práticas de lazer"31. Trata-se de uma evolução que decorreu desde o século XVIII, através das opiniões que recomendavam que o passeio dos aquistas decorresse ao ar livre e em contacto com a natureza, apesar de se manter a Copa -espaço interior onde se bebiam as águas- no interior do balneário, abrigada das intempéries mas, sobretudo, lugar imagético de identidade e celebração (Caldas de Aregos, Caldas da Rainha, Caldas de Vizela, Caldas do Gerês, Termas dos Cucos).

Em Portugal, as práticas de passeio começaram a estar associadas a espaços organizados, por exemplo em redor do Hospital Termal das Caldas da Rainha, quando, em 1799, a construção do Passeio da Copa passou a ser precursor dos passeios públicos que se espalhariam pelo século XIX nalgumas localidades portuguesas, como símbolo da civilização burguesa oitocentista, das suas preocupações com a higiene e da sociabilidade das classes ascendentes. 0 Passeio da Copa daria origem ao parque (de D. Carlos I), um século depois, que neste caso alia o valor do desenho a uma dimensão urbana de controle do espaço e socialmente mais abrangente, anunciando o seu papel futuro na cidade. Por seu turno, na mata próxima surgiram, no final do século XIX, pequenos apontamentos de "hortas botânicas", numa espécie de diálogo científico com o exotismo do espaço arbóreo global, mais espontâneo.

$\mathrm{Na}$ viragem do século XIX para o seguinte surge, então, o parque termal delimitado, invenção portuguesa com a introdução das práticas de lazer (passeios de barco em lagos, ténis, ciclismo, patinagem, etc.), que nasceram como constantes necessidades de alteração e modernização dos espaços, em complemento dos balneários, pavilhões de nascente, buvettes, galerias e hotéis _"nele existem as funções essenciais para uma estada perfeita, à luz da época; as diversas funções dão origem a diferentes formas arquitecturais, que se interligam e produzem espaços abertos ou mais íntimos, complexificam-se, transformam-se em 'cidade ideal', com as suas estruturas racionalizadas" ${ }^{32}$. Edifícios e espécies arbóreas formam um todo, existem em função uns dos outros, não tanto em termos de desenho, mas na funcionalidade que o espaço global desperta ao utente, como lugar de encontro, arte e inspiração, que acompanhou a transformação das sociedades e 0 gosto dos tempos ${ }^{33}$.

Pedras Salgadas, Melgaço, Vidago, S. Vicente, Entre-os-Rios, Curia, Carvalhelhos e Monte Real representam os mais permanentes casos desta tipologia. Na sua origem, a estância do Estoril também foi concebida como espaço delimitado, embora tenha

\footnotetext{
30 Idem.

31 Mangorrinha, 2012, 40.

32 Ibidem, 43.

33 Pinto \& Mangorrinha, 2009.
} 
perdido, mais tarde, esta característica. Representam microcosmos que funcionam como aglutinadores do espaço global. Em 2014, precisamente, passam cem anos sobre dois momentos importantes relacionados com dois desses locais. Em 1914, nas Pedras Salgadas, dá-se o fecho do gradeamento que passou a delimitar definitivamente todo o parque termal, considerado "0 primeiro parque oitocentista"34; a partir de 1879, os "pavilhões de nascente, o balneário, os hotéis, o casino e outros pequenos edifícios foram sendo construídos, a partir de eixos perpendiculares e de caminhos desenhados em relação orgânica com o terreno e preenchidos de vasta vegetação" 35 ; no Estoril, foi projectado nesse ano 0 ambicioso plano de uma estância de cariz internacional, associado à vilegiatura balnear (termal e marítima) e com base num plano global assente em todos os requisitos necessários à actividade turístico-termal, uma nova "estação marítima, climatérica, termal e sportiva”, que previa a localização em espaço delimitado de três hotéis, um novo estabelecimento termal, um casino com teatro anexo, um palácio de desportos, um edifício para banhos de mar e um amplo jardim.

\section{Epílogo}

Este preenchimento do microcosmo termal português conferiu-lhe uma característica dupla como espaço de saúde e lazer, uma concretização plena dos conceitos desenvolvidos a partir essencialmente do século XVIII e consolidado no período áureo do termalismo português. Construíram-se cenários que revelam a proeza dos seus autores e são classificados de "invenção original". Das diferentes arquitecturas projectadas e construídas nas termas portuguesas, o repertório de estilos é extenso, mas naquilo que é verdadeiramente único -o microcosmo delimitadoPortugal inovou. Importa, pois, preservá-los como património arquitectónico e cultural do termalismo europeu e da sua história.

\section{Biblografia}

Aguiar, J. 1943: Memória Descritiva e Justificativa do Plano Geral de Urbanização da Fonte Santa (Monfortinho), 7 de Julho.

Alves, O. D. 1951: "A assistência termal em Portugal”, in Revista Clínica, Higiene e Hidrologia. Novembro [S.l., s.n.].

Cavaco, C. 1980: "O turismo em Portugal: aspectos evolutivos e espaciais", sep., in Estudos italianos em Portugal, 40-42 [S.l., s.n.].

Cohen, E. 1995: "Contemporary tourism -trends and challenges, sustainable authenticity or contrived pos-modernity?", in Butler, R. \& Pearce, D. (eds.): Change in Tourism. People, Places, Processes. London/New York, Routdlegde.

Cunha, L. 1973: "Hierarquização das estâncias termais portuguesas", sep. Rev. Corporação, Transportes e Turismo, 2, Lisboa [s.n.]

Cunha, L. 1981: "As Estâncias Termais na Perspectiva do Turismo", in Jornadas do Termalismo Português. Lisboa, Associação Nacional dos Industriais de Águas Minero-Medicinais e de Mesa.

34 Mangorrinha, 2012, 45.

35 Idem.
Direcção Geral das Obras Públicas e Minas. 1914: Boletim de Minas (1912). Lisboa, Direcção Geral de Minas e Serviços Geológicos.

Direcção Geral de Minas e Serviços Geológicos. 1981: Boletim de Minas, 18, 3, Julho/Setembro. Lisboa, Direcção Geral de Minas e Serviços Geológicos.

Enzensberger, H. M. 1996: "A Theory of Tourism”, in New German Critique, 68, 117-135 (1. ${ }^{\mathrm{a}}$ ed. 1958), [s.l.], New German Critique, Inc.

Estoril. Estação Marítima, Climaterica, Thermal e Sportiva, 1914. Lisboa, Typ. A Editora Limitada.

Guia das aguas minero-medicinaes dos Cucos proximo de Torres Vedras: sua composição, qualidade e applicações...,1892. Lisboa, Typ. da Companhia Nacional Editora.

Henriques, F. F. 1726: Aquilegio medicinal, em que se dá noticia das agoas de Caldas, de fontes, rios, poços, lagoas e cisternas do Reyno de Portugal e dos Algarves que, ou pelas virtudes medicinaes que tem, ou por outra alguma singularidade, são dignas de particular memoria. Lisboa, Officina de Musica.

Mangorrinha, J. 2012: 0 que é uma cidade termal? [s.l.], J. Mangorrinha.

Molina Villar, J. J. 2004: "Termalismo y turismo en Catalunya: un estudio geohistórico contemporáneo", tesis doctoral, Universitat de Barcelona, Barcelona.

Morais, J. C. T. 1943: “Águas minerais. Sua origem”, sep. Publicações do Instituto de Climatologia e Hidrologia da Universidade de Coimbra, VII. Coimbra, Tip. da Atlântida.

Ortigão, R. 1875: Banhos de caldas e águas mineraes. Guia do banhista e do viajante. Porto, Magalhäes \& Moniz.

Panorama: revista portuguesa de arte e turismo, II, 10-11, 1954. Lisboa, Secretaria de Estado da Informação e Turismo.

Pinto, H. G. \& Mangorrinha, J. 2003: "Álbum das Termas", in Álbum das termas: na colecção do Centro Português de Fotografia / The spas photo álbum. Lisboa, Assírio \& Alvim.

Pinto, H. G. \& Mangorrinha, J. 2009: 0 desenho das termas: história da arquitectura termal portuguesa / Drawing the spas. Lisboa, H. G. Pinto \& J. Mangorrinha.

Portugal, J. C. \& Brito, J. J. 1949: Anteplano de Urbanização das Termas do Carvalhal, Novembro, cit. Acciaiuoli, L. 1946: Hidrologia Portuguesa.

Quintela, M. M. 2001: "Turismo e Reumatismo: etnografia de uma prática terapêutica nas Termas de S. Pedro do Sul”, in Etnográfica, V, 2, 359-374.

Rotureau, A. 1864: Des Principales Eaux Minérales de l' Europe. Paris, Victor Masson et fils.

Sánchez Ferré, J. 2000: “Historia de los Balnearios en España. Arquitectura, Patrimonio, Sociedad”, in Geta, J. A. L. \& Pinuaga Espejel, J. I. (eds.): Panorama actual de las Aguas Minerales y Minero-medicinales en España. Actas de las II Jornadas sobre Aguas Minerales y Minero-Medicinales, La Toja, Outubro de 1999. Madrid, Instituto Geológico y Minero de España, 213-230.

Santos, J. M. F. 2001: "Transformaçoes Contemporâneas da Experiência Turística", tese de doutoramento, Universidade Nova de Lisboa, Lisboa.

Silva, M. E. 1948: "0 Turismo em Lisboa”, in Primeira Reunião Olisiponense - Teses, Estudos e Comunicações, I. Lisboa, Câmara Municipal de Lisboa. 